\title{
A Study on Mechanical Properties of Heat Treated Vegetable Oil Quenched Medium Carbon Low Alloy Steels
}

Authors

\author{
Naveena H S ${ }^{1}$, Raghavendra $P$ Nilugal $^{2}$, Harish $K R^{3}$, Shashi Kiran $G^{4}$ \\ ${ }^{12,3,4}$.Assistant Professors, Department of Mechanical Engineering, Sri Venkateshwara College Engineering, \\ Bangalore, Karnataka, India \\ Email-- naveena407@gmail.com, ${ }^{2}$ raghunilugal@ gmail.com, ${ }^{3}$ k.r.harish025@gmail.com, \\ ${ }^{4}$ kiiran.mech@gmail.com
}

\begin{abstract}
The medium carbon low alloys steel has found enormous application in automotive, aerospace, structural engineering, agricultural engineering, railways, and marine and power sectors applications due to high strength specific mechanical properties. Medium carbon low alloy steel are family of ultra-high strength steels which includes AISI 4140(EN19) and AISI 4340(EN 24) where EN 19 is Nickel free steel and EN 24 has very low percentage of steel. Here an attempt is made to study the mechanical properties such as impact strength, tensile strength, hardness by experimental approach of heat treated medium carbon low alloys steel quenched in different types of vegetable oils. Specimens for testing are prepared from 2 rods of EN 19 and EN 24 (Rolled Condition) of $20 \mathrm{~mm}$ diameter and one and half meter length selected from yard. The specimens are machined according to the standard dimensions.

Different heat treatment processes will be carried out in different stages. Then the heat treated specimens will be quenched in vegetable oils such as sunflower oil, coconut oil, peanut oil. Specimens will be tested to study the mechanical properties. Impact test will be carried out with the help of Charpy impact test machine, Izod impact test machine, tensile test will be carried with the help of tensometer. Hardness test will be carried out with help of Brinell hardness testing machine. The results will be compared between rolled condition and heat treated oil quenched EN 19 and EN 24 medium carbon low alloys steels.

Keywords - Medium Carbon Low Alloy Steels, EN 19 and EN 24, Vegetable Oils, Heat Treatment, Quenching
\end{abstract}

\section{INTRODUCTION}

Steel is usually defined as an alloy of iron and carbon with the carbon content between a few hundreds of a per cent up to about 2 weight $\%$. Other alloying elements can amount in total to about 5 weight $\%$ in low-alloy steels and higher in more highly alloyed. Steels such as tool steels and stainless steels. Steels can exhibit a wide variety of properties depending on composition as well as the phases and micro constituents present, which in turn depend on the heat treatment. Steel has a major influence on our lives, the cars we drive, the building we work in, the homes in which we live and countless other facets in between. Steel is used in our electricity power line towers, natural gas pipelines, machine tools and military weapons. Steel is by far the most important, multifunctional and most adaptable of materials. The various uses of steel which in turn is a measure of adaptability of steel can be judged from the characteristics of steel like hot and formability, weldability, suitable machinability, hard tough and resistance, corrosion resistant, heat resistant and resistance to deformation at high temperature. 


\section{LITERATURE SURVEY}

S.B. Agboola: A research has been made on the hardening characteristics of medium carbon steel using neem oil as quenching medium has been investigated

M.B.Ndaliman: A proposal has been made to the mechanical properties of medium carbon steel were investigated under two different quenching media (water and oil).

T.Sendhilkumar\&T.K.Ajiboye: A study was made on the importance of various forms of heat treatment operations on medium carbon steel in order to forester the problem that may arise in making a wrong choice of the steel materials.

\section{MATERIALS}

Table 1: Chemical composition of EN 19 and EN 24 medium carbon low alloy steels

\begin{tabular}{|l|l|l|l|l|l|l|l|l|l|}
\hline Steel & $\% \mathrm{C}$ & $\% \mathrm{Si}$ & $\% \mathrm{Mn}$ & $\% \mathrm{Ni}$ & $\% \mathrm{Cr}$ & $\% \mathrm{Mo}$ & $\% \mathrm{~S}$ & $\% \mathrm{P}$ & \\
\hline EN19 & 0.35 & 0.6 & 0.65 & - & 0.3 & 0.15 & - & - & \\
\hline EN24 & 0.4 & 0.3 & 0.6 & 1.5 & 1.2 & 0.25 & 0.005 & 0.01 & \\
\hline
\end{tabular}

The medium-carbon low-alloy family of ultrahigh-strength steels includes AISI/SAE 4130 the higher-strength AISI 4140 (EN19) and the deeper hardening, higher-strength 4340. (EN24) Several modifications of the basic 4340 steel have been developed.

\section{HEAT TREATMENT PROCESS}

Heat treating is the process of heating and cooling steel to obtain desired properties. Various types of heat treatment processes are used to change the mechanical and physical properties or conditions of steel. In general, we heat treat steel in order to improve the toughness, improve the machinability, increase the hardness, refine the grain structure, increase the ductility, remove internal/residual stresses and improve the wear resistance.

- Annealing

- Normalizing

- Tempering

- Hardening

\section{Annealing}

Annealing is the process of heating steel to and holding at some specified elevated temperature and cooling fairly slowly. Metals are annealed to relieve internal stresses, soften them, make them more ductile, and refine their grain structures.

\section{Hardening}

Hardening is the process of austenitizing steel at a prescribed temperature, holding at that temperature for a length of time to homogenize the austenite, and then quenching at a fast rate enough to prevent transformation to any product other than martensite.

\section{Tempering}

Steel is usually harder than necessary and too brittle for practical use after being hardened. Severe internal stresses are set up during the rapid cooling of the metal. Steel is tempered after being hardened to relieve the internal stresses and reduce its brittleness. Tempering consists of heating the metal to a specified temperature and then permitting the metal to cool. The rate of cooling usually has no effect on the metal structure during tempering. Therefore, the metal is usually permitted to cool in still air. Temperatures used for tempering are normally much lower than the hardening temperatures. The higher the tempering temperature used, the softer the metal becomes. High-speed steel is one of the few metals that become harder instead of softer after it is tempered.

\section{Quenching}

The process of quenching steel refers to the rapid cooling from an austenitizing or solutionizing temperature to a significantly cooler temperature. For steel this refers to heating into the austenite phase field, typically to $845^{\circ} \mathrm{C}$ for AISI 4140 steel, and then rapidly cooling to a temperature below the martensite finish temperature. The purpose of quenching steel is to produce the martensitic phase that is hard and strong, while minimizing distortion and residual stress. These steels need to be tempered after quenching to increase the toughness.

\section{VEGETABLE OILS}

For quenching of medium carbon low alloy steel following oils will be used are-

Sunflower oil. 
Peanut oil.

Coconut oil.

\section{METHODOLOGY}

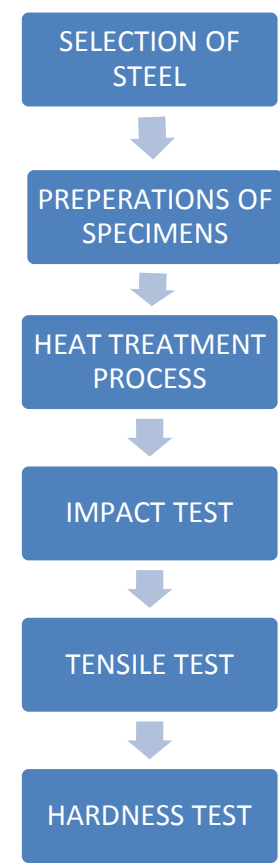

Selection of steels- Two medium carbon low alloy steels are selected for present study. EN 19 steels can be successfully nitride for maximum abrasion EN 24 are normally heat treated by quenching in oil and tempering to desired hardness these grades exhibit good response to heat treatment, especially in large sections and possess a good combination of strength ductility and roughness in the quenched and temper conditions.

Preparation of specimens- The following specimens are prepared according to required dimensions from the $20 \mathrm{~mm}$ diameter and one and half meter length rods of EN 19 and EN 24 steels with the help of lathe, milling, shaping machines.

Heat treatment processes- The materials used for heat treatment process are mainly medium alloy steels in a direct hardened, heat treated and tempered condition. Corresponding to the grade EN19 and EN24 were used. Three stages comprising three of steel rods were taken for carrying out heat treatment. All stages of samples were heated in an electric furnace to $860^{\circ} \mathrm{C}$ for 60 min. After heating, three sets of samples were taken out of the furnace.
Details of heat treatment process-

\begin{tabular}{|c|c|c|c|}
\hline Process & $\begin{array}{c}\text { Stage 1 } \\
\text { En 19\& En 24 }\end{array}$ & $\begin{array}{c}\text { Stage 2 } \\
\text { En 19\& En } \\
24\end{array}$ & $\begin{array}{c}\text { Stage 3 } \\
\text { En 19\& En } \\
24\end{array}$ \\
\hline Annealing & $\begin{array}{c}865^{\circ} \mathrm{c} \\
1 \mathrm{hr} \text { Soaking }\end{array}$ & $\begin{array}{c}865^{\circ} \mathrm{c} \\
1 \mathrm{hr} \text { Soaking }\end{array}$ & - \\
\hline Hardening & $\begin{array}{c}855^{\circ} \mathrm{c} \\
1 \mathrm{hr} \text { Soaking }\end{array}$ & $\begin{array}{c}855^{\circ} \mathrm{c} \\
1 \mathrm{hr} \text { Soaking }\end{array}$ & $\begin{array}{c}855^{\circ} \mathrm{c} \\
1 \mathrm{hr} \text { Soaking }\end{array}$ \\
\hline \multirow{2}{*}{ Tempering } & $\begin{array}{c}640^{\circ} \mathrm{c} \\
1 \mathrm{hr} \text { Soaking }\end{array}$ & - & $\begin{array}{c}575^{\circ} \mathrm{c} \\
220^{\circ} \mathrm{c} \\
1 \mathrm{hr} \text { Soaking }\end{array}$ \\
\hline \multirow{3}{*}{ Quenching } & Air & Air & - \\
\cline { 2 - 4 } & Sunflower Oil & Coconut Oil & Peanut Oil \\
\cline { 2 - 4 } & Air & - & Air \\
\cline { 2 - 4 } & & - & Air \\
\hline
\end{tabular}

\section{TESTING}

\section{Impact test}

They were prepared by notching to $2 \mathrm{~mm}$ depth at $45^{\circ}$ with the aid of the lathe machine. Four samples were prepared for each material like EN19, EN24, hardened and tempered condition as well as stage 1 , stage 2 and stage 3 condition to be used in impact test. The impact strength was measure of the energy absorbed by the specimen when it failed as a result of the strike on it by the pendulum of the measuring device. The specimens' dimensions were as indicated in the impact test.

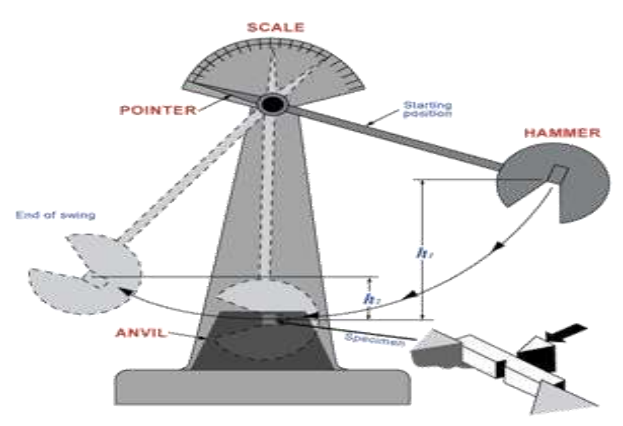

\section{Tensile test}

Tensile test is carried out with the help of tensometer on EN 19 and EN24 specimens to evaluate the ultimate strength, tensile strength, yield strength and percentage of elongation... The specimens are shown in the figure. 

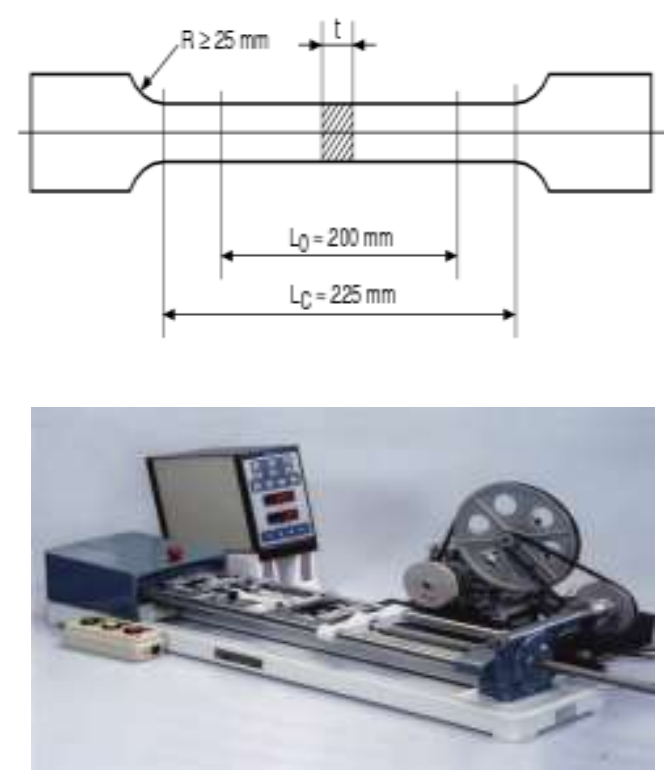

Figure 2: Tensometer

\section{Hardness test}

The Brinell test for this experiment used as a 10$\mathrm{mm}$ diameter steel ball which is pressed into a specimen by a $3000-\mathrm{kg}$ load that is maintained for 15 to 30 seconds. (A 500-kg load is used for softer, non-ferrous materials.) The Brinell hardness number (BHN) is the ratio of the load (kilograms) to the impressed area (square millimetres), and is calculated by. Equation1. Where: F: test load [kg], D: diameter of the ball [mm], Di: diameter of indentation [mm] Since the Brinell number is based on the area of indentation, the diameter of the indentation must be measured. This is done with a microscope.

The scale seen through the microscope is in millimetres. The larger diameter indentation corresponds to a softer material and lower Brinell number. The Brinell hardness number can be used to predict the tensile strength of the material. The hardness test sample-This sample is obtained by grinding the surface with emery paper, to measure the indentation of ball by using microscope.
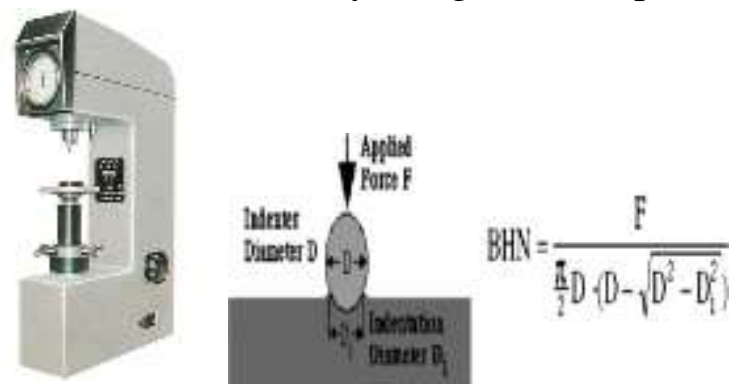

Fig 3: Brinell hardness Testing Machine

\section{RESULTS AND DISCUSSIONS}

\subsection{Impact test}

Charpy impact test machine

1 Division=2 Joules

Weight of the pendulum $=21 \mathrm{~K}$

Angle $=140$

a-Graph of Charpy Impact results of EN19 stage1, stage2, stage 3 .

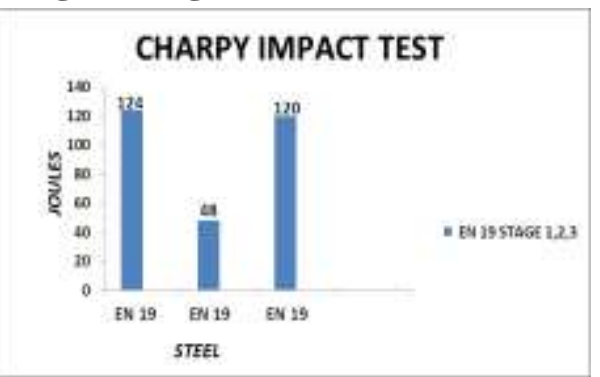

As comparing to the above results the EN19 stage1 high toughness with EN19 stage2 EN19 stage 3, due to the annealed, sunflower oil quenched and tempered condition. Due to the annealing process the strength and toughness of the material increases.

\section{b-Graph of Charpy Impact results of EN24} stage1, stage2, stage 3.

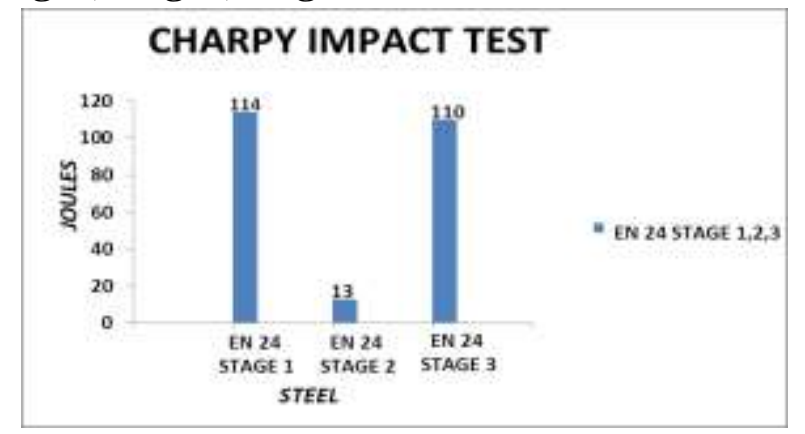

As comparing to the above results the EN24 stage1 high toughness with EN24 stage2 EN24 stage3, due to the annealed, sunflower oil quenched and tempered condition. Due to the annealing process the strength and toughness of the material increases.

\section{Izod impact test machine}

1 Division=2 Joules

Weight of the pendulum $=21.5 \mathrm{Kg}$ 
c) Graph of Izod impact results of EN19 stage1, stage2, stage 3 .

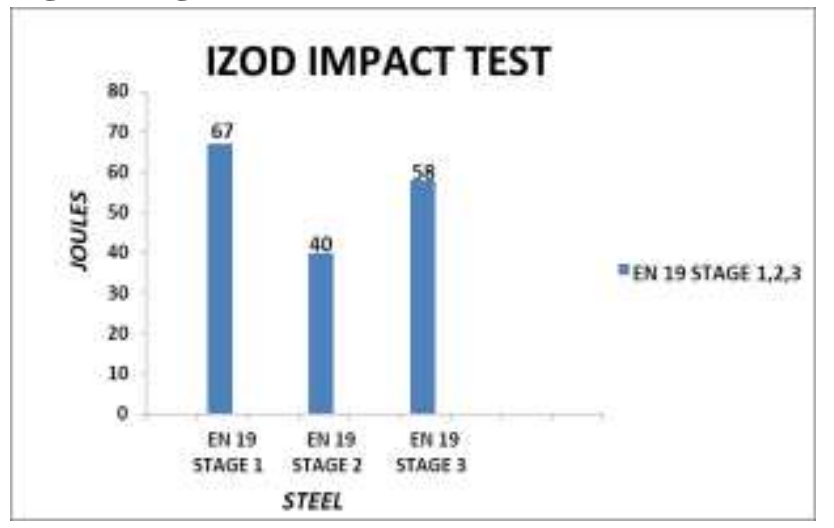

As comparing to the above results the EN19 stage1 high toughness with EN19 stage2 EN19 stage 3 , due to the annealed, sunflower oil quenched and tempered condition. Due to the annealing process the strength and toughness of the material increases.

d) Graph of Izod impact results of EN24 stage1, stage 2 , stage 3

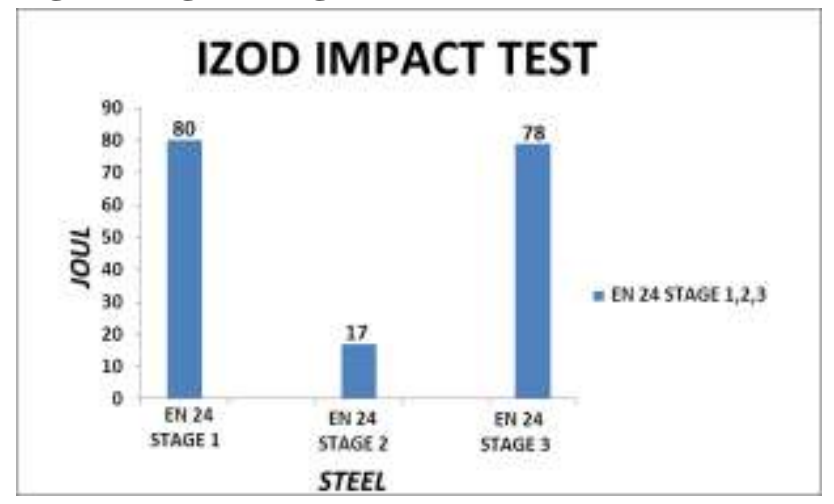

As comparing to the above results the EN24 stage1 high toughness with EN24 stage2 EN24 stage3, due to the annealed, sunflower oil quenched and tempered condition. Due to the annealing process the strength and toughness of the material increases.

\subsection{Tensile test}

a) Graph of ultimate tensile strength of EN 19 stage 1, 2 and 3

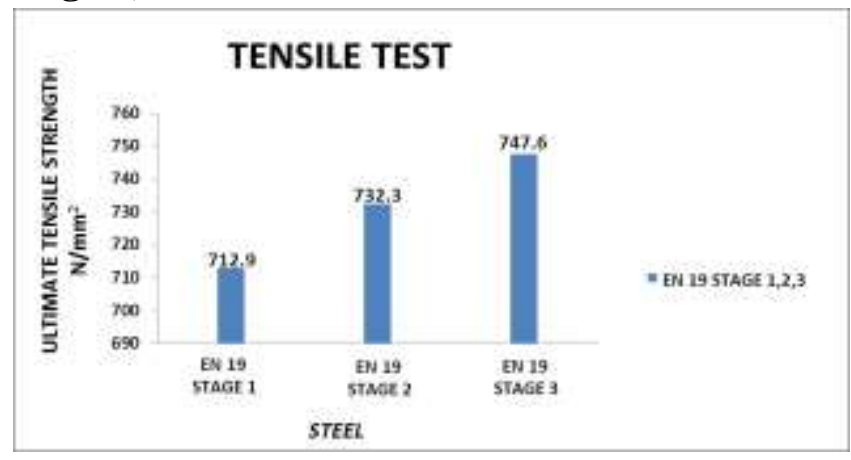

As compare to above results EN19 stage2 has high ultimate tensile strength without tempering.

b) Graph of Yield strength of EN 19 stage 1, 2 and 3

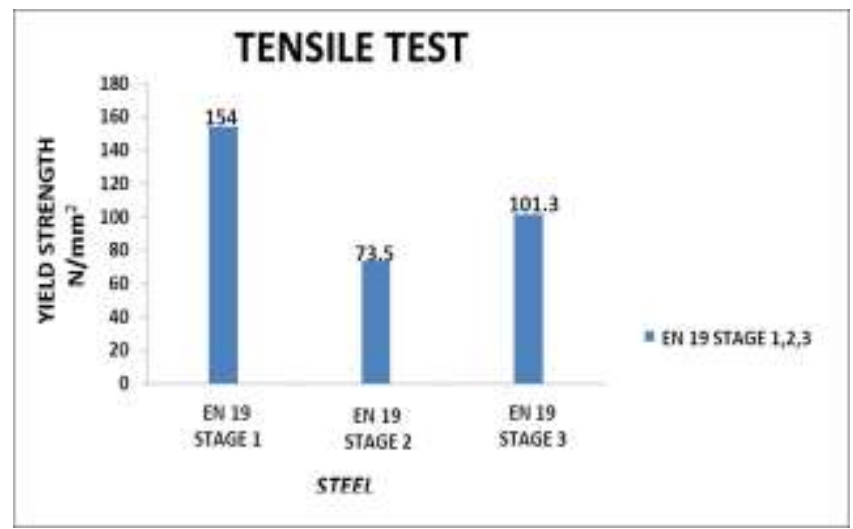

As compare to above results EN 19 stage 3 having high yield strength due to step tempering

c) Graph of ultimate tensile strength of EN 24 stage 1, 2, and 3

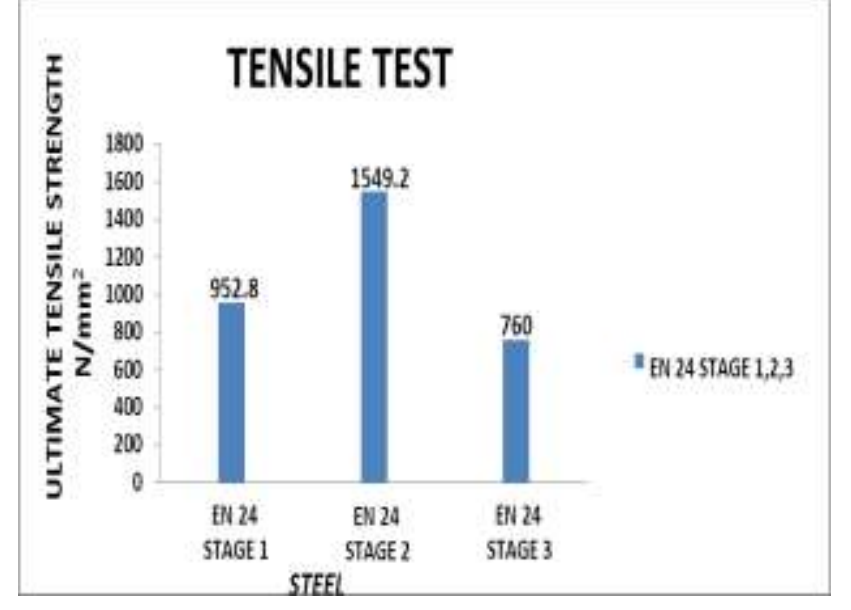

As compare to above results EN 24 stage 2 has high tensile strength due to without tempering.

d) Graph of yield strength of EN 24 stage 1, 2, 3

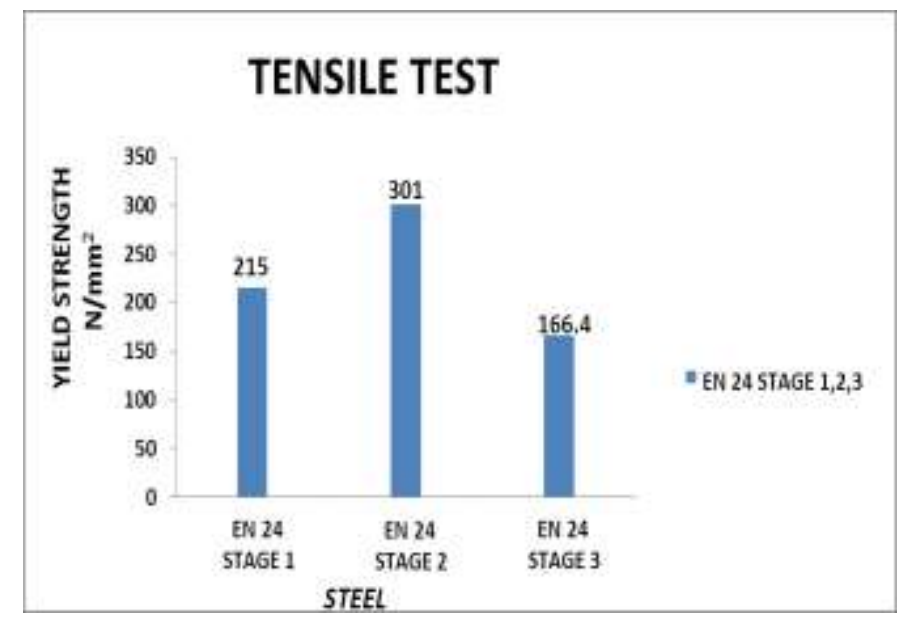

As compare to above results EN 24 stage 2 having high yield strength due to without tempering. 


\subsection{Hardness test}

BHN for EN 19 and EN 24 stage 1, stage 2, stage 3

\begin{tabular}{|c|c|c|}
\hline Steel/load & $1000 \mathrm{~kg}$ & $1500 \mathrm{~kg}$ \\
\hline EN 19 STAGE 1 & 154 & 147 \\
\hline EN 24 STAGE 1 & 201 & 267 \\
\hline EN 19 STAGE 2 & 154 & 156 \\
\hline EN 24 STAGE 2 & 315 & 341 \\
\hline EN 19 STAGE 3 & 179 & 248 \\
\hline EN 24 STAGE 3 & 154 & 176 \\
\hline
\end{tabular}

Here we observed that EN 24 stage 1 for different loads the BHN increases because of the hardenability due to annealing, hardening, tempering and quenching with sunflower oil.

EN I9 stage 2 for different loads the BHN decreases and EN 24 stage 2 for different loads BHN increases due to without tempering. EN 19 and EN 24 stage 3 for $1000 \mathrm{~kg}$ and $1500 \mathrm{~kg}$ the BHN increases.

\section{CONCLUSIONS}

- EN 24 stage1 has good charpy and Izod impact strength.

- EN 24 stage 2 have good ultimate tensile strength than EN 24 stage 2 and EN 24 stage 1 and EN 19 stage 1,EN 19 stage 2,EN 19 stage 3

- EN 24 stage 1 have good BHN values

- Izod impact strength of EN 19 stage 1 and EN 24 stage 1 have good impact values compared with EN 19 and EN 24 of stage 2 and stage 3.

- EN 19 rolled condition has higher values of Ultimate tensile strength as compared with EN 24 rolled condition.

- Ultimate tensile strength of EN 19 stage 3 have high value as compared to EN 19 stage 1 and EN 19 stage 2 and yield strength of EN 19 stage 1 have high value as compared with EN 19 stage 2 and EN 19 stage 3.

- EN 24 stage 2 have higher values of Ultimate tensile strength and yield strength as compared with EN 24 stage 1 and EN 24 stage 3

- EN 19 and EN 24 rolled condition for different loads the BHN values increases but compare those values EN 19 rolled condition have higher BHN values compared to EN 24 rolled condition

- EN 19 stage 1 and EN 24 stage 1 for different loads the BHN values increases but compare those values EN 24 stage 1 have higher $\mathrm{BHN}$ values as compared to EN 19 stage 1.

- EN 19 stage 2 for different loads the BHN values decreases and EN 24 stage 2 for different loads increases due to without tempering.

- EN 19 and EN 24 Stage 3 BHN values increases due to step tempering and quenching with peanut oil.

\section{REFERENCES}

1. Torsten Ericsson, "Principle of heat treating of steels", ASM handbook Volume 4 (1991 Edition) pg 14-25

2. T V Rajan, C P Sharma and Ashok Sharma, "Chapter 1 - Introduction", Heat treatment principles and techniques.

3. "Effect of heat treatment process on the mechanical properties of medium carbon steels"- T. Sendhil Kumar1, and T.K Ajiboye2.

4. "Evaluation of mechanical properties of medium carbon steel quenched in water and oil"- J K Odusote1, T.K Ajiboye2.

5. "Microstructural evolution and mechanical properties of low alloy steel tempered by induction heating"- Soon Tae Ahna, Dae Sung Kimb, Won Jong Namb.

"Assessment of quench severity of vegetable oil blends for heat treatment of steels"- Prabhu K Narayan. 